\title{
Reescrituras de la respiración: el intercambio digital entre Cristina Rivera Garza y Lina Meruane.
}

\section{Towards New Ways of Breathing: The Digital Exchange Between Cristina Rivera Garza and Lina Meruane.}

\author{
David Loría Araujo \\ Departamento de Letras / Universidad Iberoamericana (MÉXICO) \\ CE: dloriaa@hotmail.com ID ORCID: 0000-0003-0624-9918
}

DOI: $10.32870 /$ sincronia.axxiii.n76.12b19

(C) $\mathrm{BY} \cdot \mathrm{NC}$

Esta obra está bajo una Licencia Creative Commons Atribución-NoComercial 4.0 Internacional

Recibido: 03/11/2018

Revisado: 07/03/2019

Aprobado: 08/04/2019

\begin{abstract}
RESUMEN
Este artículo tiene por objetivo confrontar las lecturas del cuerpo en dos figuras autoriales contemporáneas Ilamadas Cristina Rivera Garza y Lina Meruane. En las autoras, mexicana y chilena, existe una conciencia del cuerpo y su lectura como texto inconcluso, en tránsito. La experiencia de vivir un lenguaje alterno en los actuales lugares de residencia de ambas, se traduce en otras formas de mirar, de nutrir y de respirar en el texto. El corpus analizado se compone de ocho correos electrónicos, cuatro de cada escritora, en los que existe una conciencia sobre la encarnación del cuerpo autorial en la página.
\end{abstract}

Palabras clave: Literatura latinoamericana. Figura autorial. Autorías encarnadas. Representaciones intermediáticas. 


\begin{abstract}
:
This article aims to confront the body's readings in two contemporary authorial figures called Cristina Rivera Garza and Lina Meruane. In the authors, Mexican and Chilean, there is a consciousness of the body and its reading as an inconclusive text, in transit. The experience of living an alternative language in the current places of residence of both, becomes other ways of looking, nourishing and breathing in the text. The corpus analyzed consists of eight emails, four from each writer, in which there is an awareness of the embodiment of the authorial body on the page.
\end{abstract}

Keywords: Latin American Literature. Authorship. Embodied Authorships. Intermediatic Representations.

El autor vuelve de entre los muertos no para vivir, sino para desvivir o, incluso, por paradójico que parezca, para desvivirse. (Rivera, 2013, p.57).

Hace cinco años, entre febrero y marzo de 2013, Cristina Rivera Garza (México, 1964) y Lina Meruane (Chile, 1970) intercambiaron correos electrónicos con el objetivo de hacer pública una conversación al respecto de su práctica literaria. La correspondencia fue provocada y gestionada por los narradores Rodrigo Hasbún y Rodrigo Fuentes, creadores de la revista electrónica Traviesa. Literatura contemporánea de cerca. ${ }^{1}$ El archivo de este epistolario está actualmente disponible, en formato bilingüe, en la sección "Intercambio"² del portal web. En los ocho mensajes digitales,

\footnotetext{
${ }^{1}$ Este Artículo se inscribe en un trabajo de investigación más amplio y detallado sobre la revista electrónica, que se define como "un parque de diversiones literarias". En una entrada de su blog No hay tal lugar, con fecha del 24 de septiembre de 2013, Cristina Rivera Garza señala que este sitio web "atraviesa, y de manera por demás traviesa, géneros y geografías" ( $\mathrm{s} / \mathrm{p})$.

${ }^{2}$ La revista puede ser estudiada como parte de los que Meri Torras Francés y Aina Pérez Fontdevila, al decir de José-Luis Diaz, señalan como "dispositivos escenográficos" (Pérez y Torras, 2016, p.26) en tanto que contribuye con la conformación y la "representación de la figura autorial" $(2016$, p.31) de cara al público lector. Las diversas secciones del sitio web acercan a los lectores y las lectoras a un encuentro con la figura autorial que tiene pretensiones lúdicas. Ahí está, por ejemplo, el apartado "Entrevista", en la que se archivan las conversaciones vía Skype con autoras y autores como Leila Guerrero, Samanta Schweblin, Alberto Fuget o Valeria Luiselli; o la sección "Pregunta", en la que diferentes escritores y escritoras, como Andrea Jeftanovic, Luis Felipe Fabre, Liliana Blum o Diamela Eltit nombran a los personajes
} 
cuatro de cada emisora, Meruane y Rivera Garza conversan, entre muchos otros temas, sobre los soportes de la literatura, los procesos sinuosos de la memoria o los retos de la teoría frente a la literatura contemporánea. Así mismo las escritoras, Lina desde la costa nordeste de Estados Unidos y Cristina desde Oaxaca, reflexionan acerca de la relación entre escritura y cuerpo -específicamente entre el ritmo del texto y la respiración de su autor- y del devenir que se activa en ambos elementos a lo largo de un proceso creativo.

En un texto que pudo haberse llamado "Nadie me verá cartear" o "Tinta en el ojo" intervenciones a los títulos más celebrados de ambas autoras ${ }^{3}$ pero que lleva el nombre de "Sin sello postal: la correspondencia digital entre Lina Meruane y Cristina Rivera Garza", Marcela Beltrán Bravo (2016) analiza algunos de los aspectos enlistados de esta conversación. Según señala la autora, el intercambio Rivera Garza vs. Meruane "contextualiza los momentos en que ambas autoras coincidieron en reuniones literarias, ponencias o entregas de premios" (2016, p.2). Del mismo modo, Beltrán Bravo destaca que "la forma de escribir las cartas es distinta en cada autora" y que, además, las escritoras “aprovechan y modifican la escritura epistolar" (Beltrán, 2016, p.3). Estamos frente a un discurso producido a cuatro manos que reconfigura la estructura del género y que combina $-\mathrm{y}$ difumina los límites entre- la autoficción, la metaliteratura, el ensayo y el epistolario.

A la zaga del "efecto boomerang" que proponen Aina Pérez Fontdevila y Meri Torras Francés (2016, p.11) para la figura autorial en los estudios literarios contemporáneos, el siguiente artículo tiene por objetivo analizar las reflexiones que a partir del ejercicio mencionado comparten Lina Meruane y Cristina Rivera Garza sobre la construcción de una identidad autorial y su impacto en la obra literaria. En las siguientes líneas, analizaremos este epistolario virtual a la manera de un

con los que les gustaría tomarse una cerveza o revelan a qué se habrían dedicado en caso de no vivir de la escritura. En la sección "Intercambio", de la que nos ocuparemos en esta ponencia, figuran nueve archivos de correspondencia electrónica, entre los que se encuentra el diálogo entre Mario Bellatin y Edmundo Paz Soldán. Como indica Marcela Beltrán Bravo, el de Cristina Rivera Garza vs. Lina Meruane, "es el único epistolario entre dos mujeres que se dedican a la escritura" (2016, p.1).

${ }^{3}$ El guiño de Marcela Beltrán Bravo se dirige hacia Nadie me verá llorar (1999) y Sangre en el ojo (2012), de Rivera Garza y Meruane, respectivamente. El texto al cual hago referencia se presentó en formato de ponencia en el VIII Congreso Internacional de Literatura en la Feria Internacional de la Lectura Yucatán. 
estudio de caso o, para usar un término de Eleonora Cróquer Pedrón, de un "caso de autor", 4 de un caso de autoras.

La dinámica del "carteo" entre las escritoras, la exposición de sus correos electrónicos y, aún más, la disponibilidad de éstos en la web y la presunta intención de ser publicados con valor literario, operan como "dispositivos escenográficos" (Pérez y Torras, 2016, p.26); es decir, como un soporte o plataforma que, "como la entrevista o la visita al escritor; [...] como la prensa o la fotografía" (Pérez y Torras, 2016, p.31) se encuentran al servicio de la representación del autor o autora. Tal como indican Pérez y Torras (2015), este role-play es "producto de las 'elecciones'” del candidato a escritor, de sus reconfiguraciones a lo largo de su trayectoria autorial y del remodelaje que [...] realiza el lector" (p.6).

Observaremos la correspondencia electrónica de la escritora mexicana y la escritora chilena en dos sentidos: por un lado, como "camerino" a partir del cual cada una modela su avatar autorial; y por otro, como "proscenio", en función de la escenificación de un "ethos discursivo", al decir de Dominique Maingueneau (2016), una situación comunicativa o un comportamiento verbal en donde "cada toma de palabra implica una construcción de identidad a través de las representaciones que se hacen el uno del otro los participantes de la enunciación" (p.133) y que se encarna o involucra una "incorporación" (Maingueneau, 2016, p.140). Debido a lo anterior, el interés particular de este análisis recae en el "enfoque aparentemente sesgado o periférico" (Pérez y Torras, 2015, pp.1-2) que intersecta los estudios de autor con los estudios del cuerpo. En palabras de Pérez y Torras, la articulación entre autoría y corporeidad consiste en "la consideración del autor (de su corpus pero también y sobre todo de su cuerpo) como objeto o artefacto cultural" (p.7). Con base en los e-mails, vamos a leer a las autoras $-\mathrm{y}$ a las representaciones de sus cuerpos-como textos, producciones

\footnotetext{
${ }^{4}$ En el artículo "Currículum Vitae. Notas para una definición del 'caso de autor", Cróquer Pedrón se refiere a "un tipo particular de autoría literaria y artística que se verifica en la historia cultural latinoamericana" (2016, p. 107), "un archivo -híbrido y heterogéneo, abigarrado y heterotópico- que termina convirtiendo el acontecimiento del cual se supone que da cuenta (la obra-vida de un creador excéntrico) en una extraña configuración de "texto-con-cuerpo" [...] que da de qué hablar a la cultura" (Cróquer, 2016, p.107). Este proceso, construido "en complicidad" (Cróquer, 2016, p.111) entre los autores y sus gestores culturales, se puede localizar en los "casos" de Delmira Agustini, Frida Kahlo o Clarice Lispector, por mencionar algunas.
} 
textuales en constante reescritura. Prestaremos especial atención a las reflexiones que Lina y Cristina comparten al respecto de la respiración y su reconocimiento como proceso estructural y estructurante de la escritura.

En la madrugada del 25 de febrero de 2013, Meruane da inicio al intercambio con una confesión: "me resulta algo incómodo entablar una conversación por esta vía" (2013, s/p). Lo anterior se debe a que, más allá de un par de encuentros culturales adjetivados por Lina como "solemnes", es poco lo que ambas autoras se conocen. El primero fue en Nueva York, donde compartieron una mesa panel sobre el cuento; el segundo, en Guadalajara, durante la entrega del Premio Sor Juana Inés de la Cruz, que Meruane recibió de manos de Rivera Garza por su novela Sangre en el ojo, en el marco de la Feria Internacional del Libro en 2012. La autora chilena menciona estos recuerdos, que detonarán en su interlocutora la reflexión sobre el tema de la respiración.

Un día después, por la mañana, Cristina dice acordarse de Nueva York, pero no del tono, el ritmo y el volumen de la escritora chilena, una voz -entre huraña y tierna- que sí recuerda haber escuchado años más tarde en la FIL de Guadalajara:

De esos días de NY, no recuerdo, sin embargo, tu voz, Lina. Y lo digo porque fue eso, la voz, el ritmo de la voz, la manera en que tu voz asciende y desciende, vertiginosa, lo que traje tuyo de Guadalajara. La había leído, claro, desde la primera frase de tu libro. La voz. Lo que uno llama "un ritmazo" queriendo decir "ese modo de respirar" [...] Una enunciación particular. Un cierto volumen, incluso. Algo de beligerancia y otro tanto de los arranques que a veces provoca la timidez. [...] Pues eso, que en NY no estaba, o que no la recuerdo de entonces, ese ritmo, esa voz. ¿Surgió después? ¿Estaba distraída yo y no la noté? ¿La escondiste entonces? (Rivera Garza, 26 de febrero 2013, s/p)

Al parecer, según Rivera Garza, el "modo de respirar" de Meruane se relaciona directamente con la hechura de la obra literaria, se sedimenta en la escritura, va de los pulmones de la autora a la página de la novela. La forma y el impacto de la voz en el texto pueden, como sugiere Cristina, evolucionar, acentuarse, esconderse. A pesar de los cuestionamientos finales, la emisora reconoce que no hay en ellos un interés por respuestas ni verdades concretas: 
Todas esas preguntas no las puede responder ni La Memoria ni La Verdad. Lo único cierto, la única prueba empírica (se dice así), es que está ahí, en el libro, entre los puntos y los puntos y comas, y las comas, los súbitos cortes de frase y de párrafo que son, a fin de cuenta, el esqueleto de Sangre en el ojo. (Rivera, 26 de febrero 2013, s/p)

El corpus de la novela referida estriba en los soportes simbólicos, que articulan la construcción de los sintagmas en el texto: aceleran, fragmentan, ralentizan, encauzan. Sin que importe la posibilidad de comprobarlo, para Rivera Garza, el esqueleto de la escritura está directamente relacionado con el corpus de Lina Meruane. Cristina intuye que, como la identidad del sujeto, la respiración -y su representación en el cuerpo del texto- muta, deviene otra: "Lejos de ser natural o, como se dice, propia, la respiración se aprende y/o cambia con el tiempo" (Rivera Garza, 26 de febrero 2013, s/p). De igual manera, líneas más adelante inquiere: “¿Qué otra cosa es la puntuación en la página sino la respiración del texto?" (Rivera Garza, 26 de febrero 2013, s/p). Luego, Meruane le contestará: "Lezama Lima decía que su ritmo barroco, su voz puntuada de comas, era un efecto del asma que sufría. Una manifestación" (28 de febrero 2013, s/p).

Cristina menciona sus hábitos deportivos y recalca que practicar la natación en Oaxaca la ha hecho más consciente de sus nexos con el aire y la respiración. Así mismo, confía en el influjo de estos descubrimientos sobre su labor literaria:

Supongo (o espero) que esa conciencia pasará de alguna forma (nada o poco consciente) al territorio de la página después: cómo colocar la palabra aquí o allá para, por ejemplo, acentuar el flujo del líquido-lenguaje, o cómo detener el paso para evitar la presencia nerviosa de esas olas pequeñitas que solo estorban. (Rivera Garza, 26 de febrero 2013, s/p)

En los fragmentos anteriores, observamos una conciencia de autora que, tal como propone Meri Torras (2015a), se trata de una "derivación textual-corporal" (p.23); es decir, "un ser, estar y devenir configurado textualmente" (Torras, 2015a, p.36). En el actual retorno, o en la "des-muerte" (Rivera, 2013) contemporánea de la figura autorial, la mirilla se encuentra puesta en las reconfiguraciones del cuerpo del autor en tanto ser-vivo-que-escribe y que, como se pone de manifiesto en esta 
correspondencia, está presente en las preocupaciones de Meruane y Rivera Garza. Acerca de este regreso autorial, José-Luis Diaz (2016) señala que:

El autor que "vuelve" no es, con certeza un sujeto-dueño, ni una autoridad jurídica suprema, responsable del conjunto de enunciados que circulan bajo su nombre. No es, ya, un héroe épico provisto de un destino. Pero tampoco es, sin embargo, un simple scripteur, un puro gestor del texto. $Y$, aunque uno desconfíe siempre de su antiguo poder, le permite recobrar de contrabando algunas de sus funciones tradicionales. $Y$ en primer lugar su estatuto de ser vivo. (Díaz, 2016, p.70)

Ante la provocación de Rivera Garza y consciente de la inestabilidad de su voz en el material literario, la escritora chilena especula -en su segundo e-mail y tercer correo del archivo- sobre el viaje como otra forma de activar el devenir de la voz y la respiración:

Hay algo en los tiempos del viaje. Para mí salir de casa es cambiar de frecuencia. Entrar en otra frecuencia, en otro tiempo o en otra disposición temporal. [...] Viajar para apagar algunas voces y permitirse escuchar otras, a veces la propia. Un ausentarse de la incesante conversación que se mantiene con otros por escrito y volver a la voz del interior sin tanta meditación, sin tanta exposición. [...] Producir una voz, aprender a respirar, Cristina, ¿no es lo que venimos haciendo? (Meruane, 28 de febrero 2013, s/p)

Para las interlocutoras, tanto nadar como viajar implican ejercicios de la respiración. “Aprender a respirar mientras corremos de un lado a otro" dice Meruane a Rivera Garza (28 de febrero 2013, s/p), "buscar la puntuación dentro del desplazamiento tan acelerado. Y aprender a respirar de una manera propia, buscar el propio ritmo, sin respiraciones ajenas" (28 de febrero 2013, s/p). Lina interrumpe su mensaje en repetidas ocasiones para realizar una cartografía de su viaje en tren desde New Haven hasta Nueva York. Incluye mensajes en cursivas como "Próxima estación: Milford", "Estamos llegando ahora a Bridgeport" o "Paramos en Fairfield Metro". De esta forma, como intuye Beltrán Bravo, "la estructura propuesta por Meruane se va complejizando y alejando de la estructura tradicional de la carta, volviéndola un texto híbrido con apartes teatrales y con 
información sobre el contexto de producción de la escritura" (2016, p.4). Cuando retoma el hilo de lo que Rivera Garza rememora, Meruane revela: "tampoco recuerdo mi voz de entonces, ni la tuya de entonces, Cristina" (28 de febrero 2013, s/p). En busca de una impronta de aquella memoria sonora, Lina recurre al texto y rastrea una voz que deviene cuerpo y no sólo se escucha sino que huele, asoma, estalla y escurre:

Tengo todavía el texto que leí esa noche. Volví a mirarlo ahora para verificar si ya estaba ahí lo que tú piensas como mi voz. ¿Estaba o no estaba ahí? Tenía que haber estado, asomando ya los puños. Una no se escucha la voz, no percibe el acento propio. No se huele, pero a veces sí se huele, ¿no? A veces sí se escucha. Quizá simplemente el volumen era más bajo y simplemente estalló ahora. Quizás todos los libros anteriores son preparaciones, lentas afinaciones y modulaciones de la voz. (Meruane, 28 de febrero 2013, s/p)

Para Mayte Cantero Sánchez (2015), como para las corresponsales, “la autoría está [...] conformada y confirmada por un corpus-cuerpo [...] que llega a la voz y se da a la voz" (p.137). En el caso de Lina, la pesquisa se dirige hacia las huellas de una identidad -sonora y corpórea- que se sabe evasiva y transitoria pero, sobre todo, relacional. La sospecha del otro (en este caso, Rivera Garza), hace que Meruane esculque en su cuerpo-texto, no para encontrar una explicación biografista y determinista, sino para mapear el devenir de su figura autorial. A juicio de Cantero Sánchez,

se pueden rastrear las marcas de un cuerpo sin el cual la escritura no tendría lugar, de una escritura como rastro o gesto, lo cual no significa que sea la vida previa al texto la que otorgue sentido a la obra. (2015, p.138)

En ese tenor, la escritora chilena imagina el cuerpo de Rivera Garza al nadar y con ello reanuda el asunto de la respiración:

Escribo esto y te pienso en traje de baño, zambulléndote en esas aguas frías, tratando de controlar la respiración que se corta por el frío, respirar para sobreponerse al golpe de la temperatura. Eso también se hace al escribir: encontrar un ritmo para sobreponerse a la inclemencia de la fría página en blanco (Meruane, 28 de febrero 2013, s/p). 
Siguiendo a Cantero Sánchez, "existe un cuerpo en medio (no previo a) de la obra; esto es, la corporeidad de todo corpus literario conduce a la comprensión del artefacto cultural como una manifestación concreta, cooriginaria de un individuo" (2015, p.137). En este punto, Meruane introduce otro elemento que imbrica al cuerpo y a la voz: la relación con el lugar de nacimiento y desarrollo del sujeto autor, y las apropiaciones o desapropiaciones que éste hace del acento, la cadencia y la modulación "de origen":

¿Cuán determinada está tu respiración por la oralidad de la patria, por el canto propio de la primera lengua? Yo que hace doce años vivo fuera de Chile pienso que mi respiración literaria ha ido recuperando un cierto sonsonete. $Y$ no hablo acá de una mímesis costumbristas sino de un respirar o de un puntuar que identifico o imagino como chileno. Esto, que ya estaba pero que era prácticamente inaudible en los libros que escribí estando todavía en Chile se ha agudizado dramáticamente. Hay un regocijo con ese ritmo achuecado, ese zapateo de la lengua que es lo único que extraño de Chile. Porque yo misma he modulado mucho mi manera de pronunciar el español y entonces al escribir evoco esa pérdida cotidiana. (Meruane, 28 de febrero 2013, s/p)

Para el tiempo en el que se escribió esta correspondencia, Meruane impartía talleres de escritura creativa en Nueva York y Rivera Garza formaba parte del claustro de profesores del campus San Diego de la Universidad de California. Con base en estas posiciones leídas como extranjeras, ¿cómo pensar en la acentuación literaria, esa forma de colocar los signos y las tildes, y su relación afectiva -rechazada, añorada o recuperada- con el origen que es, a todas luces, corporal? Interesada por la potencia sonora de la alteridad, Meruane indaga: "Me pregunto si te pasa esto a ti también, Cristina, si tu respiración, en el agua o en la página, es cada vez más mexicana. [...] Repito, Cristina: tú que has vivido lejos tanto tiempo, más tiempo que yo, pienso" (Meruane, 28 de febrero 2013, $\mathrm{s} / \mathrm{p})$.

El jueves 28 de febrero a las 15:25, sin embargo, Rivera Garza discurre sobre sus memorias de aquél encuentro en Nueva York y el recuerdo de la muerte de Daniel Sada. Por lo tanto, en la 
siguiente carta, enviada el 1 de marzo a las 12:23 horas, Meruane insiste: "Cuéntame de lo otro, de la lengua, de cómo te mueves entre ellas, cuando puedas, tengo curiosidad por saber cómo vives y escribes entre ellas... porque también yo vivo y escribo entre dos o tres o tantas" (s/p). Una hora más tarde -y después de compartir un enlace al video del último lanzamiento de David BowieCristina responde con una disertación a propósito de un trabajo crítico de la poeta estadounidense Juliana Sphar:

Se trata de esa peculiar gama de escritores que decidieron alejarse, voluntariamente, del inglés promedio no para discurrir sobre su identidad, sino para decir algo sobre la lengua, sobre el idioma, sobre el cómo nos hace nosotros en contextos desiguales y dinámicos. Esos escritores alejados del inglés promedio escriben con lo que ella llama "la inquietante dislocación gramatical" [...] de la migración. (Rivera Garza, 1 de marzo 2013, s/p)

De la cita anterior nos importa, por un lado, destacar el reconocimiento que la autora otorga al potencial agramatical de la escritura; es decir, la posibilidad que tiene el texto de negociar con los términos de la inteligibilidad, pero atreviéndose a torcer los constructos y desafiar los límites de ésta. Por otro lado, nos interesa yuxtaponer las palabras de Rivera Garza con las que Gilles Deleuze menciona, haciendo alusión explícita a Proust, en el prólogo a Crítica y clínica de 1993: “El escritor [...] inventa dentro de la lengua una lengua nueva, una lengua extranjera en cierta medida. Extrae nuevas estructuras gramaticales o sintácticas. Saca a la lengua de los caminos trillados, la hace delirar" (Deleuze, 1996, p.9). Sobre su propia experiencia delirante, Rivera Garza revela:

Creo que poco a poco, pero de manera inexorable, me he ido alejando no sólo del español promedio, sino también del inglés promedio (de los libros promedio ya estaba lejos desde antes, creo yo). Vivo desde hace ya muchos años (tal vez ya más de la mitad de mi vida) en un ir y venir constante; un vaivén que no cesa; una oscilación que no me interesa ni detener ni, en realidad, nombrar. (Rivera Garza, 1 de marzo de 2013, s/p)

Para la autora mexicana, el movimiento pendular, entre lenguajes y territorios, se convierte en una postura política - pero también, y aún más, en una postura como la entiende Jérôme Meizoz 
$(2016)^{5}$ - que se propone el abandono a la "instrumentalización del lenguaje" (Rivera Garza, 2013, p.21) y privilegia la intervención lúdica, estratégica, movediza e inestable del repertorio gramatical asignado a la identidad y sus normas lingüísticas. De conformidad con lo que propone en su libro de ensayos Los muertos indóciles. Necroescrituras y desapropiación, sobre las "escrituras que exploran el adentro y el afuera del lenguaje, [...] su acaecer social en comunidad, justo entre los discursos y los decires de los otros en los que nos convertimos todos cuando estamos relacionalmente con otros" (Rivera Garza, 2013, p.25). Desde este esta posición que renuncia -al menos discursivamente- a la autoría como autoridad, Rivera Garza dice a Meruane: "en lugar de tomar el camino del dominio sobre las cosas y las lenguas, he optado por algo que le cae mejor a mi trabajo y a mi vida: la vulnerabilidad. La vulnerabilidad como método, digámoslo así" (Rivera Garza, 1 de marzo 2013, s/p). Con respecto a este ethos discursivo, las compiladoras del monográfico Autoría y género de la revista Mundo Nuevo, afirman que:

Devenir autor es un proceso que no tiene lugar en la habitación propia, aislada, de la escritura, sino en la escena social y política, [...] en la cual la autorialidad depende de la mirada ajena y [...] de la institución de una imagen reconocible y doblemente impropia: construida mediante relatos colectivos, y vulnerable a las múltiples reelaboraciones y reescrituras de los agentes del campo cultural. (Cróquer, Pérez y Torras, 2015, p.24)

Para la autora mexicana, esta vulnerabilidad, asumida como postura, también se convierte en poética que se vuelca y se derrama en su producción literaria:

La segunda lengua, que puede ser el español cuando estoy en Estados Unidos, o el inglés cuando estoy en México, o viceversa, me ha ayudado a generar una manera de atención al lenguaje [...] que en mucho beneficia (o mancha, según lo veas), los libros que acabo escribiendo. (Rivera Garza, 1 de marzo 2013, s/p).

\footnotetext{
${ }^{5}$ Para el investigador francés, la postura (posture) "es la manera singular de ocupar una "posición" en el campo literario. [...] Quien imprime una obra [...] impone una imagen de sí mismo que va más allá de su identidad civil. [...] La postura constituye la "identidad literaria" construida por el autor mismo y, en la mayoría de los casos, retomada por los medios" (Meizoz, 2016, p.190). Así mismo, Meizoz aclara que la adopción de una postura es "parte constitutiva del acto creador" y que "se construye conjuntamente con una poética" (2016, p.204).
} 
Antes de finalizar el intercambio electrónico, las autoras retoman la temática del cuerpo. ${ }^{6}$ Marcela Beltrán Bravo destaca la importancia de los recuerdos sensoriales en estos correos y señala que "los cinco sentidos se activan a partir del tejido del recuerdo con la lluvia, la conversación, la comida" (2016, p.6). En su penúltima carta, Cristina construye la siguiente imagen de su relación con San Diego, donde vivió por mucho tiempo:

Recuerdo el día [...] en que, por ejemplo, empecé a querer a San Diego luego de una larga relación tentativa y, más bien, ambivalente. Fue un romance que empezó con una esquina de la mesa de madera donde solía escribir. Se lo dije así a un amigo que no me preguntaba eso, pero como estaba sorprendida por el proceso, por su irrupción impremeditada, hice lo que sé hacer: escribir. Le dije que estaba pasando, que justo en ese momento estaba queriendo como nunca antes, tal vez como nunca después, esa esquina de la mesa, y veía ya venir el afecto primero, y luego el amor desbordado, por la superficie entera, la silla, el piso que sostenía la silla, la puerta, la banqueta, la calle. Lo veía venir, dije, y eso fue lo que vi días o meses después. Es raro cómo pasan a veces las cosas. (Rivera Garza, 1 de marzo 2013, s/p)

La autora disecciona los detalles de este descubrimiento y los relata como un encuentro afectivo. Así mismo, reconoce su facultad para traducir el acontecimiento del cuerpo a la página: un talento, una necesidad. Más adelante, Lina Meruane se refiere al estreno de su obra de teatro Un lugar donde caerse muerta (Not a Leg to Stand On) (2012) en los Estados Unidos, y dice que había sido "una experiencia muy extraña ver que las palabras estaban vivas, que tenían cuerpo". (Meruane, 4 de marzo 2013, s/p). Esta serie de enunciados, en los que el cuerpo de las autoras se pone en texto y viceversa, también puede ser pensado en clave de rúbrica, como "conjunto de rasgos que acompañan la firma" (Torras, 2015a, p.26), que por su etimología remite a la impronta carnal del autor en la escritura.

\footnotetext{
${ }^{6} \mathrm{Al}$ respecto de esta intersección entre cuerpo-escritura, que atraviesa indefectiblemente por los terrenos del afecto, Deleuze considera que "el problema de escribir tampoco es separable de un problema de ver y oír: en efecto, cuando dentro de la lengua se crea otra lengua, el lenguaje en su totalidad tiende hacia un límite [...] 'agramatical'"' (1996, p.9).
} 
Las últimas citas de la correspondencia, nos sirven para recuperar la hipótesis con la que hemos leído este epistolario digital. Desde una óptica general, el intercambio funciona como un performance autorial que se compone de dos momentos entrelazados. El de un self-fashioning: ${ }^{7}$ un "camerino" a través del cual, desde su computadora, tableta o celular, las escritoras diseñan su personaje-autora y focalizan los temas que les interesan para la adopción de una postura; y el del diálogo frente al público: "un proscenio" que nos convierte en testigos de un ethos al que, a pesar de estar viendo las bambalinas, otorgamos una credibilidad y un valor literario. El conjunto de estos procesos corresponde a lo que Meri Torras reconoce como el "segundo oficio" del escritor:

El posar ante los objetivos fotográficos, saber construirse en los medios, mostrarse de determinada manera en la esfera pública parece pues imprescindible para llamarse escritor o para, como puntualiza José-Luis Diaz, hacerse llamar escritor. Se reconocido como tal. (Torras, 2015b, p.87)

A guisa de conclusión, es preciso reconocer que, en primer lugar, la disponibilidad de este tipo de intercambios reactualiza las líneas epistemológicas para quienes, desde la sociología literaria o el análisis crítico del discurso, se dedican a los estudios de autoría; en segundo lugar, que falta por realizar un análisis comparativo entre el diálogo creativo y teórico que se produce en esta escenificación epistolar y lo que cada autora lleva a la praxis en sus obras publicadas, específicamente en materia de la conciencia del cuerpo, su lectura como texto en tránsito y su encarnación en la escritura. En tercer lugar, que lo ya dicho sobre estos correos no soslaya la sospecha sobre la factibilidad del autor para dar cuenta de sí mismo; por último, y en relación con lo anterior, que esta correspondencia contribuye a que los sintagmas "Lina Meruane" y "Cristina

\footnotetext{
${ }^{7}$ Ingo Berensmeyer, Gert Buelens y Marysa Demoor, miembros del grupo Research on Authorship Studies, proponen la lectura de la autoría como un performance cultural a partir del cual, para ser considerado como tal, el autor o autora "depende de una determinada configuración de la sociedad, de una determinada mediatización de las actividades literarias, de determinados desarrollos tecnológicos, y de ciertas características discursivas" (2016, p.239). Todos estos elementos coadyuvan a la formación de una "topografía cultural" (Berensmeyer, Buelens y Demoor, 2016, p.239) que se repite, se instituye, se normaliza y hace aparecer al autor o autora en el mapa.
} 
Rivera Garza" aparezcan como artefactos autoriales, como sellos que otorgan visibilidad y les producen un presente mediático.

El lunes 4 de marzo, a las 10:19 de la mañana, Lina comienza a despedirse, no sin mencionar el backstage que hizo posible y fiscalizó el carteo:

Me escribe quien nos invitó a conversar y me pregunta cómo vamos en esta conversación, luego me dice que nos hemos alargado demasiado que tenemos que empezar a cortar. Empiezas tú o empiezo yo, la edición. Lamento tener que despedirme, pero me despido igual. Y te abrazo hasta el próximo correo, un correo que empezará a ser privado. (Meruane, 4 de marzo 2013, s/p)

El correo final es de Cristina quien, antes de dar por terminada la conversación pública, se declara interesada en continuar con el intercambio en esa zona intersticial y agramatical de la lengua que ambas comparten:

Digamos, entonces, que la cosa se interrumpe, ¿no te parece? Porque yo deseo seguir platicando contigo de esto y de lo otro y de aquello y mucho más en el futuro cercano y no tan cercano. Esto de vivir dentro de Estados Unidos y de continuar participando en una conversación escritural que se hace en español es algo que compartimos, y no es cosa menor. (Rivera Garza, 5 de marzo 2013, s/p).

\section{Referencias}

Beltrán, M. (2016). "Sin sello postal: la correspondencia digital entre Lina Meruane y Cristina Rivera Garza". En VIII Congreso Internacional de Literatura en la Feria Internacional de la Lectura Yucatán.

Berensmeyer, I., Buelens, G. y Demoor, M. (2016). “La autoría como performance cultural: nuevas perspectivas en estudios autoriales", Gama M. (Trad.). En M. Torras y A. Pérez (Comps.) Los 
papeles del autor/a. Marcos teóricos sobre la autoría literaria. (pp. 205-239). Madrid: Arco Libros.

Cantero, M. (2015). "'Salvo si susurra...': reformulaciones contemporáneas de la instancia autorial". En Tropelías. Revista de Teoría de la Literatura y Literatura Comparada, (24). pp. 134-139. Cróquer, E. (2016). “Currículum Vitae, Notas para una definición del "caso de autor”. En M. Torras Francés y A. Pérez Fontdevila (Comps.) Los papeles del autor/a. Marcos teóricos sobre la autoría literaria. (pp. 107-128). Madrid: Arco Libros.

Cróquer, E., Torras, M., y Pérez Fontdevila, A. (2015). “Ninguna voz es transparente. Autorías de mujeres para un corpus visibilizador". En Mundo Nuevo, Revista de Estudios Latinoamericanos, año VII(16). pp. 15-27.

Deleuze, G. (1996). “Prólogo”. Crítica y clínica, Thomas Kauf (Trad.). Barcelona: Anagrama.

Díaz, J.L. (2016). “Las escenografías autoriales románticas y su 'puesta en discurso'”. En M. Torras Francés y A. Pérez Fontdevila (Comps.) Los papeles del autor/a. Marcos teóricos sobre la autoría literaria. (pp. 155-186). Madrid: Arco Libros.

Maingueneau, D. (2016). “El ethos: un articulador". En M. Torras Francés y A. Pérez Fontdevila (Comps.) Los papeles del autor/a. Marcos teóricos sobre la autoría literaria. (pp. 131-153). Madrid: Arco Libros.

Meizoz, J. (2016). “¿Qué entendemos por postura?”. En M. Torras Francés y A. Pérez Fontdevila (Comps.) Los papeles del autor/a. Marcos teóricos sobre la autoría literaria. (pp. 187-204). Madrid: Arco Libros.

Meruane, L.; y Rivera, C. (2013). “Intercambio”. En Traviesa. Literatura Contemporánea de cerca. Recuperado de http://www.mastraviesa.com/Intercambio-Meruane-vs-Rivera-Garza-1 Pérez, A.; y Torras, M. (2016). “Hacia una biografía del concepto de autor”. En M. Torras Francés y A. Pérez Fontdevila (Comp.) Los papeles del autor/a. Marcos teóricos sobre la autoría literaria. (pp. 11-51). Madrid: Arco Libros. 
Pérez, A.; y Torras, M. (2015). “La autoría a debate: textualizaciones del cuerpo-corpus (una introducción teórica)". En Tropelías. Revista de Teoría de la Literatura y Literatura Comparada, (24). pp. 1-16.

Rivera, C. (2013). Los muertos indóciles. Necroescrituras y desapropiación. México: Tusquets.

Torras, M. (2015a). "Y el verbo se hizo carne. Vías de encarnación de un corpus-cuerpo autorial”. En Estudios. Revista de investigaciones literarias y culturales. 21(42). pp. 23-41.

Torras, M. (2015b). "El segundo oficio del escritor. Photo-Photo, de Marie Mimier, o la textualización de la pose autorial". Tropelías. Revista de Teoría de la Literatura y Literatura Comparada, (24). pp. 84-92. 